\title{
A STUDY ON LOW-COMPLEXITY TRANSMIT ANTENNA SELECTION FOR GENERALIZED SPATIAL MODULATION
}

\author{
Adewale Alafia*, Simeon ajose and Agbotiname imoize \\ Department of Electrical and Electronics Engineering, Faculty of Engineering, \\ University of Lagos, Akoka Lagos, Nigeria. \\ *Corresponding author: adealafia@yahoo.com
}

(Received: $19^{\text {th }}$ Feb 2018; Accepted: $20^{\text {th }}$ July 2018; Published on-line: $1^{\text {st }}$ Dec 2018)

https://doi.org/10.31436/iiumej.v19.i2.899

\begin{abstract}
Generalized spatial modulation (GSM) maps its information to the index of the transmit antenna combination, making simultaneous transmission of multiple symbol possible. However, SM outperform GSM scheme in terms of error performance of the same data rate, due to average power effect. Transmit and receive diversity or the combination of both allow huge improvement in mimo systems in terms of error performance. In this paper, we investigate a near optimal low-complexity Euclidean distance antenna selection (LC-EDAS) technique in GSM system, to further improve the performance of the conventional GSM system. The LC-EDAS technique independently search across signal and spatial dimension to eliminate the worse channel prior to transmission. Secondly, we investigate a sub-optimal low-complexity transmit antenna selection (LCTAS) in the GSM system to further reduce the computational complexity (CC) imposed by LC-EDAS. The Monte Carlo simulation results obtained reveals a tradeoff between the GSM scheme with LC-EDAS and GSM scheme with sub-optimal transmit antenna selection in terms of error performance and CC.
\end{abstract}

ABSTRAK: Modulasi Spatial Keseluruhan (GSM) menghubung informasi kepada indeks kombinasi antena yang dipancarkan, membuatkan pemancaran keseluruhan simbol dapat dilakukan. Walau bagaimanapun, SM lebih bagus daripada skim GSM pada prestasi kesilapan pada kadar data yang sama, kerana kesan purata kuasa. Kepelbagaian penghantaran dan penerimaan ataupun kombinasi keduanya memberi pembaharuan yang lebih besar dalam sistem mimo pada prestasi kesalahan. Penyelidikan ini akan mengkaji optima terdekat Euclidean kurang rumit, melalui teknik (LC-EDAS) pilihan jarak antenna dalam sistem GSM, bagi menambah prestasi sistem GSM sedia ada. Teknik LC-EDAS secara sendiri mencari signal dan dimensi separa bagi mengurangkan saluran lebih teruk semasa penghantaran. Kedua, kami mengkaji sub-optima proses pemilihan kurang rumit penyebaran antena (LCTAS) dalam sistem GSM bagi mengurangkan kerumitan pengiraan (CC) yang dikenakan oleh LC-EDAS. Keputusan simulasi Monte Carlo yang diperoleh menunjukkan timbangan antara skim GSM dan LC-EDAS dan skim GSM bersama suboptima proses pemilihan penyebaran antena berdasarkan kesilapan prestasi dan CC.

KEYWORDS: multi-input multiple-output; computational complexity; spatial modulation; Euclidean distance antenna selection; transmit antenna selection

\section{INTRODUCTION}

In the past decade, the wireless communication sector has been categorized as the fastest growing sector in the communication industry. This is due to the need for 
improvement in next generation wireless devices in terms of speed, reliability, and throughput [1]. This led to multiple-input multiple-output (MIMO) systems [2]. MIMO systems exhibits great potential with respect to high throughput and improved reliability in wireless communication [2]. The benefit of employing a MIMO system lies on the fact that an improved error performance and high throughput coupled with improved diversity gain can be achieved. However, in MIMO systems, the simultaneous transmission of data requires the need for inter-antenna synchronization (IAS) and the channel will experience an inter-channel interference (ICI) at the receiver [1,2]. Hence, it is clear that the dominant consideration in wireless technology is to employ a system that is able to mitigate these impairments.

Lately, the use of multiple antennas has been investigated in numerous papers as the future of wireless communication [2]. This led to the development of an improved MIMO system called spatial modulation (SM) [3], which employs its spatial dimension to convey additional information improving the major drawback of conventional MIMO systems. However, the SM system also has a drawback of high complexity, due to the number of required transmit antennas to transmit high data streams [3]. This brought about the generalized spatial modulation system (GSM) [4]. The GSM system [4-6], is an SM-based scheme that maps its information bits to the index of the transmit antenna combination, thus reducing the required number of transmit antennas for high data streams. However, SM outperforms the GSM system in terms of error performance.

The attractive features of SM and GSM include avoidance of ICI and IAS, which formed the major limitation of conventional MIMO systems. GSM exhibits significant improvement when compared to a conventional SM in terms of CC [3,5]. The constraint of a large number of transmit antennas required in SM was improved on in GSM $[4,5]$. The complexity of the GSM system is still not practically implementable.

In literature $[7,8]$, incorporating a transmit antenna selection (TAS) into a MIMO system can further enhance the performance of the system. This is evident in $[9,12]$, where SM was introduced as an improved MIMO scheme. However, practical realization was still a problem due to high $\mathrm{CC}$ imposed by the system. In [9], a maximum ratio combining (MRC), was introduced to an SM system, to initially estimate the index of the transmit antenna, which was later employed to detect the transmitted symbol. The result obtained exhibited an improved error performance and the imposed CC was greatly reduced. Similarly, in [10], TAS was employed in SM to improve the performance of the system, employing a channel amplitude technique to eliminate the worst channel at every transmission instant.

Transmit and receive diversity or a combination of both in spatial multiplexing allow huge improvement in terms of error performance [7]. Employing TAS in selecting subset of antennas combination has proven to be extremely beneficial for link initialisation and maintenance [10,11]. Likewise, employing TAS has shown to increase the achieved diversity gain [12]. The selection criterion proposed in [13] was based on the Shannon capacity, and as such, yielded optimal capacity gain. In addition, in [14], a selection criterion that minimised the probability of symbol error rate (SER) for spatial multiplexing systems is investigated.

In [12], the availability of additional antennas is revealed as an inexpensive way of exploiting diversity advantage. This was corroborated in [15], whilst further proving that the diversity of space shift keying (SSK) can be improved by increasing the number of surplus transmit antennas. Furthermore, TAS, which maximised the minimum Euclidean distance (ED) of a received constellation to yield an optimal performance, considers ED as 
a function of both the received constellation and the channel. As a result, the ED criterion selects an optimal antenna subset in terms of the minimum error rate [16]. This is evident in [17], where an optimal performance was achieved in the SM system by employing a decision metric that maximized the minimum ED among the transmit vectors. This scheme also increased the diversity order of SM system but at a cost of high complexity.

In this study, a low-complexity Euclidean distance antenna selection (LC-EDAS) is introduced to the GSM system to further improve the performance of the system by splitting the exhaustive search of EDAS into signal, spatial, and joint evaluation. This allowed an independent search across signal, spatial, and joint (signal and channel) to reduce the CC imposed on the system similar to [18].

Secondly, we investigate a sub-optimal transmit antenna selection in the GSM system. Employing channel amplitude and antenna correlation to further reduce the high $\mathrm{CC}$ imposed by LC-EDAS. The Monte Carlo simulation result obtained reveals a trade-off in terms of performance and CC between the GSM scheme with LC-EDAS and GSM scheme with sub-optimal transmit antenna selection.

The structure of the remainder of the paper is as follows: in section 2, the system model for the proposed scheme is presented. In section 3, the numerical analysis of the system is presented. In section 4 , the CC of the system is presented. In section 5, a summary of findings of the proposed scheme is presented while conclusions are drawn in section 6.

\section{SYSTEM MODEL OF THE PROPOSED SCHEME}

In the GSM system, information bits are mapped into the transmit antenna combination, making the transmission of two symbols possible at the same time. Thus, reducing the required number of transmit antennas to transmit a high data rate.

\subsection{Transmission Model of GSM System}

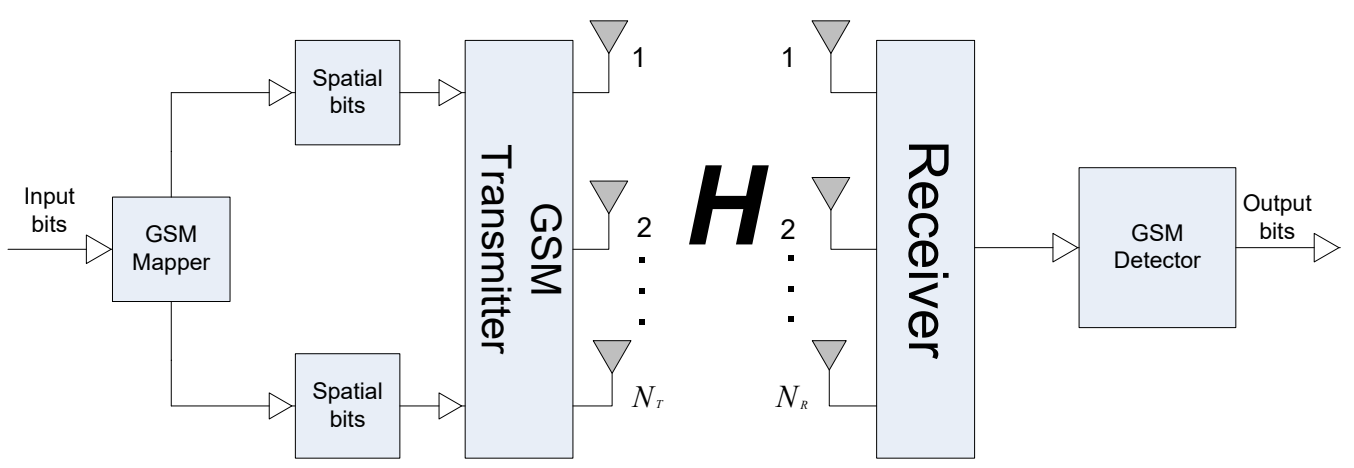

Fig. 1: System model for a conventional GSM system [4].

Figure 1 reveals a conventional GSM system, which is equipped with $N_{T}$ transmit antennas and $N_{R}$ receive antennas, respectively. The spectral efficiency of the GSM system is $m=\log _{2}(M)+\left\lfloor\log _{2}\left(\begin{array}{c}N_{T} \\ 2\end{array}\right)\right\rfloor \mathrm{b} / \mathrm{s} / \mathrm{Hz}$. For example, consider a GSM system with a configuration setting of $4 \times 4,4$-QAM. The spectral efficiency yielded will be $4 \mathrm{~b} / \mathrm{s} / \mathrm{Hz}$, in which the first two bits are used to select the active antenna combination and the last two bits are used to select the constellation symbol $x_{q}$ to be transmitted via a Rayleigh fading channel $\boldsymbol{H}$ of dimension $N_{R} \times N_{T}$, where $N_{R}$ and $N_{T}$ is the number of transmit and receive antennas, respectively. In the presence of an additive white Gaussian noise (AWGN) $\boldsymbol{n}$. In 
this paper, we considered same symbol to be transmitted at both transmit antenna combination at the same time.

The received signal vector $\boldsymbol{y}$ becomes:

$$
\boldsymbol{y}=\sqrt{\rho / \mu} \boldsymbol{H} x_{q}+\boldsymbol{n}
$$

$\rho / \mu$ is the average signal-to-noise ratio (SNR) and $x_{q}=\left[x_{1} x_{2}\right]$. The transmitted signal can be detected optimally, employing maximum likelihood (ML) such that all possibilities are estimated across all the signal space similar to SM. This can be expressed as [4]:

$$
\left[j, x_{q}\right]=\underset{\ell_{1}, \ell_{2}, x_{1}^{q}, x_{2}^{q}}{\operatorname{argmin}}\left(\left\|\boldsymbol{y}-\sqrt{\rho / \mu}\left(\boldsymbol{H} x_{q}\right)\right\|_{F}^{2}\right)
$$

\subsection{Transmit Antenna Selection for GSM System}

Figure 2 reveals a conventional GSM system, equipped with $N_{T}$ transmit antennas and $N_{R}$ receive antennas, respectively, together with an antenna selection module and a feedback link.

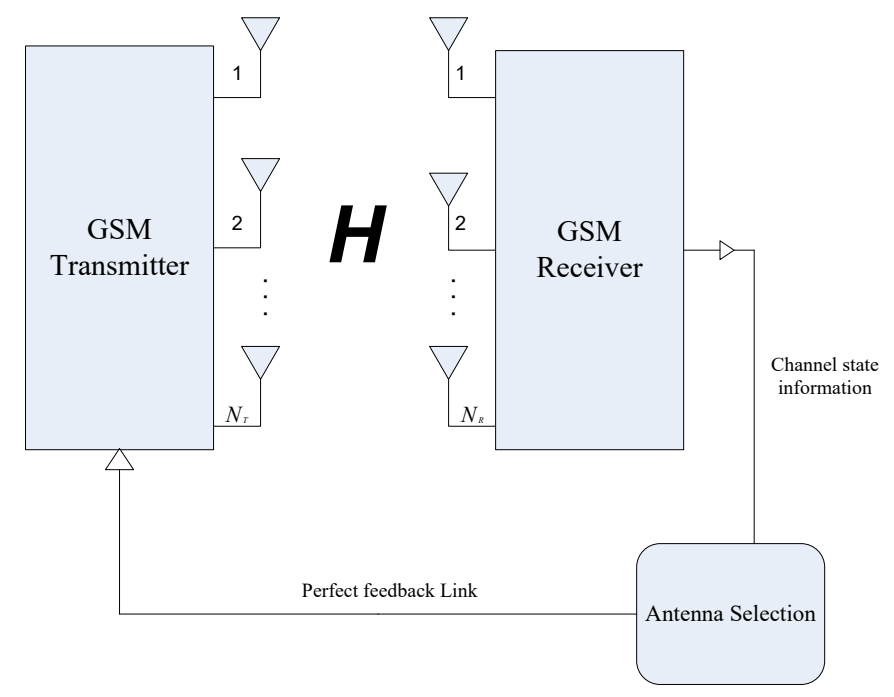

Fig. 2: System model for the proposed LC-GSM system.

In literature $[15,17]$, it has been stated that TAS can improve the error performance of a spatial multiplexing system. In [19], EDAS was employed to select the transmit antenna combination in GSM system. The error performance achieved in the scheme is superior but the CC imposed on the system is high. However, in [18], LC-EDAS was investigated in SM, imposing a much lower $\mathrm{CC}$ and exhibiting a performance near to that of the EDAS SM scheme of [16].

The GSM system exhibits less error performance compared to SM due to the average power effect, but required less transmit antenna to achieve a high data rate. This motivates us to investigate LC-EDAS in the GSM system to further improve the performance of the system.

Secondly, a low-complexity TAS (LCTAS), employing the combination of channel amplitude and antenna correlation to eliminate the worse channel at every transmission 
instant in order to maximize transmit diversity of the GSM system to attain a performance similar to SM system is investigated in the GSM system. The CC imposed by this scheme is lower than LC-EDAS approach but the performance achieved is also lower than that of the LC-EDAS system. The Monte Carlo simulation results reveal the trade-off between CC and error performance with LC-EDAS and LCTAS.

\subsubsection{LC-EDAS for GSM System}

In [18], the instantaneous SER for each candidate subsets was computed into signal, spatial, and joint minimum squared Euclidean distance denoted as $E D_{\text {signal }}^{2(\ell)}(\boldsymbol{H})$, $E D_{\text {spatial }}^{2(\ell)}(\boldsymbol{H})$ and $E D_{\text {Joint }}^{2(\ell)}(\boldsymbol{H})$, respectively. The receiver employs the channel estimates to select a subset $\ell \in 1: N_{S}, N_{S}=\left(\begin{array}{c}N_{\text {Total }} \\ 2\end{array}\right)$ and $N_{\text {Total }}>N_{T}$. We employ a similar approach to [18], to compute the three minimum squared Euclidean distance for signal, spatial and joint, respectively for the GSM system, maximizing the minimum Euclidean distance employing singular value decomposition for the joint evaluation. The close form of expression of the formulated $E D_{G S M-\text { signal }}^{2(\ell)}(\boldsymbol{H}), E D_{G S M-\text { spatial }}^{2(\ell)}(\boldsymbol{H})$ and $E D_{G S M-J o i n t}^{2(\ell)}(\boldsymbol{H})$ proceeds as:

$$
\begin{aligned}
& E D_{G S M-\text { signal }}^{2(\ell)}(\boldsymbol{H})
\end{aligned}
$$

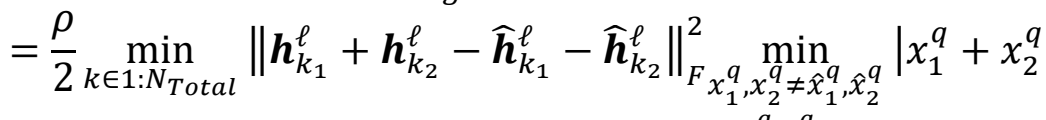

$$
\begin{aligned}
& -\hat{x}_{1}^{q}-\left.\hat{x}_{2}^{q}\right|^{2} \\
& x_{1}^{q}, x_{2}^{q} \in \chi \\
& E D_{G S M-\text { spatial }}^{2(\ell)}(\boldsymbol{H})=\frac{\rho}{2} \min _{k \in 1: N_{\text {Total }}}\left\|\boldsymbol{h}_{k_{1}}^{\ell}+\boldsymbol{h}_{k_{2}}^{\ell}-\widehat{\boldsymbol{h}}_{k_{1}}^{\ell}-\widehat{\boldsymbol{h}}_{k_{2}}^{\ell}\right\|_{F x_{q} \in \chi}^{2} \min _{1}\left|x_{1}+x_{2}\right|^{2} \\
& E D_{G S M-J o i n t}^{2(\ell)}(\boldsymbol{H})=\frac{\rho}{2} \min _{\substack{k \in 1: N_{T o t a l} \\
x_{1}^{q}, x_{2}^{q} \neq \hat{x}_{1}^{q}, \hat{x}_{2}^{q} \\
x_{1}^{q}, x_{2}^{q} \in \chi}}\left\|\boldsymbol{h}_{k_{1}}^{\ell} x_{1}^{q}+\boldsymbol{h}_{k_{2}}^{\ell} x_{2}^{q}-\widehat{\boldsymbol{h}}_{k_{1}}^{\ell} \hat{x}_{1}^{q}-\widehat{\boldsymbol{h}}_{k_{2}}^{\ell} \hat{x}_{2}^{q}\right\|_{F}^{2} \\
& \geq \frac{\rho}{2} \min _{k \in 1: N_{\text {Total }}} \sigma_{k, \hat{k}_{1}}^{2} \min _{x_{1}^{q}, x_{2}^{q} \neq \hat{x}_{1}^{q}, \hat{x}_{2}^{q}}\|\|\left[\begin{array}{c}
x_{1}^{q} \\
x_{1}^{q}, x_{2}^{q} \in \chi
\end{array}\|\|_{2}^{q}\right.
\end{aligned}
$$

where $\min _{k \in 1: N_{\text {Total }}} \sigma_{k, \hat{k}}^{2}$ is the minimum squared singular value decomposition of the channel matrix $\left[\boldsymbol{h}_{k_{1}}^{\ell}+\boldsymbol{h}_{k_{2}}^{\ell}-\widehat{\boldsymbol{h}}_{k_{1}}^{\ell}+\widehat{\boldsymbol{h}}_{k_{2}}^{\ell}\right]$ and $\ell \in\left[1: N_{T}\right]$. The channel matrix $\boldsymbol{H}$ has entries, which is modelled as an independent and identically distributed (iid) complex Gaussian random variables with $C N(0,1)$.

The next sub-section presents the algorithm for a LC-EDAS for GSM system.

\section{Algorithm 1}

Step 1: Construct an $N_{R} \times N_{T_{\text {otal }}}$ dimension channel matrix, where $N_{T_{\text {otal }}}>N_{T}$. 
Step 2: Compute the minimum squared Euclidean distance for $\operatorname{ED}_{G S M \text {-signal }}^{2(\ell)}(\boldsymbol{H})$, $E D_{G S M \text {-spatial }}^{2(\ell)}(\boldsymbol{H})$ and $E D_{G S M-J o i n t}^{2(\ell)}(\boldsymbol{H})$, respectively. Employing Eq. (3-5), considering all possible combination of $N_{s}=\left(\begin{array}{c}N_{\text {Total }} \\ 2\end{array}\right)$.

Step 3: Choose the minimum instantaneous minimum square Euclidean distance for each condition, i.e.

$$
E D_{G S M}^{2(\ell)}(\boldsymbol{H})=\min \left\{E D_{G S M-\text { signal }}^{2(\ell)}(\boldsymbol{H}), E D_{G S M-\text { spatial }}^{2(\ell)}(\boldsymbol{H}), E D_{G S M-J o i n t}^{2(\ell)}(\boldsymbol{H})\right\}
$$

Step 4: Select the antenna subset that has the largest instantaneous minimum squared Euclidean distance among the candidates in step 3, using:

$$
\ell_{\text {selected }}=\max _{\ell=1 \in N_{S}}\left\{E D_{G S M}^{2(\ell)}(\boldsymbol{H})\right\}
$$

where $N_{s}$ is the possible antenna pairs in the corresponding vectors in the channel matrix $\boldsymbol{H}$. Thus, the selected transmit antenna will be employed for transmission at the next transmission instant.

\subsubsection{TAS Based on Channel Amplitude and Antenna Correlation for the GSM System}

Employing the concept of channel amplitude with a decision of "the larger the amplitude of the channel, the better it is" as investigated in [8], and an antenna correlation, a concept was investigated in [20], transmit antennas were discarded based on high correlation. Employing both channel amplitude and antenna correlation, which are suboptimal techniques will impose a very low CC [15]. This motivates the application of this technique to the GSM system. Algorithm 2 presents the step/procedure for the implementation of the channel amplitude and antenna correlation technique.

\section{Algorithm 2}

Step 1: Construct an $N_{R} \times N_{T_{\text {otal }}}$ dimension channel matrix, where $N_{T_{\text {otal }}}$ is the total number of transmit antennas available, which is greater than $N_{T}$.

$$
\boldsymbol{H}=\left[\begin{array}{lllll}
\boldsymbol{h}_{1} & \boldsymbol{h}_{2} & \boldsymbol{h}_{3} & \ldots & \boldsymbol{h}_{N_{\text {Total }}}
\end{array}\right]
$$

Step 2: Compute the channel amplitude using $\|\boldsymbol{H}\|_{F}$ for the above channel constructed in Step 1 and sort in descending order.

Step 3: Choose $N_{T}+1$ such that the dimension matrix becomes $N_{R} \times\left(N_{T}+1\right)$, i.e.

$$
\boldsymbol{H}=\left[\begin{array}{llll}
\boldsymbol{h}_{1} & \boldsymbol{h}_{2} & \ldots & \boldsymbol{h}_{N_{T}+1}
\end{array}\right]
$$

Step 4: Calculate the angle of correlation of the channel combination similar to [21] and [22] using:

$$
\theta=\arccos \left(\frac{\left|\boldsymbol{h}_{a}{ }^{H} \boldsymbol{h}_{b}\right|}{\left\|\boldsymbol{h}_{a}\right\|_{F}\left\|\boldsymbol{h}_{b}\right\|_{F}}\right)
$$

Step 5: Arrange the angle of correlation in vectors and eliminate the smallest angle (highest correlation) from the channel $N_{T}+1$ computed in Step 4. 
The number of transmit antennas left will be employed for the next transmission instant in the GSM system, maximizing transmit diversity in the GSM system.

\subsubsection{TAS for EDAS GSM}

TAS based on EDAS, selects the subset of transmit antennas, which maximises the minimum ED between all transmit antenna vectors, achieving an optimal performance. EDAS for GSM (EDAS-QSM) is based on the nearest neighbour approximation, the PEP of GSM for a given channel $\boldsymbol{H}$ is:

$$
P_{e} \cong \lambda \cdot Q\left(\sqrt{\frac{1}{2} \min _{x_{1} \neq x_{2} \in \chi}\left\|\boldsymbol{H}^{\prime}\left(x_{1}-x_{2}\right)\right\|_{F}^{2}}\right)=\lambda \cdot Q\left(\sqrt{\frac{1}{2} d_{\text {min }}^{2}\left(\boldsymbol{H}^{\prime}\right)}\right)
$$

where $\lambda$ is the number of neighbor points and $d_{\min }^{2}\left(\boldsymbol{H}^{\prime}\right)=\min _{x_{q_{1}} \neq x_{q_{2}} \in \chi}\left\|\boldsymbol{H}^{\prime}\left(x_{1}-x_{2}\right)\right\|_{F}^{2}$ is the squared minimum Euclidean distance between the pair of neighbor symbols.

In maximizing the minimum Euclidean distance, the selected antennas can be chosen using:

$$
d_{\min }^{2}\left(\boldsymbol{H}^{\prime}\right)=\min _{\substack{\left.x_{1} \neq x_{2} \in \chi \\ \ell \in 1: N_{s}\right] \\ x_{1} \neq x_{2} \\ q \in 1: M}}\left\|\boldsymbol{h}_{\ell_{1}} x_{1}+\boldsymbol{h}_{\ell_{2}} x_{2}-\boldsymbol{h}_{\hat{\ell}_{1}} x_{\widehat{1}}-\boldsymbol{h}_{\hat{\ell}_{2}} x_{\widehat{2}}\right\|_{F}^{2}
$$

\section{NUMERICAL ANALYSIS}

The Monte Carlo simulation results obtained from this research work are presented in this section. The notation $N_{R} \times N_{T}$ is used to denote the number of receive antennas and transmit antennas, respectively. This algorithm was adopted from the literature $[9,11,20]$. The proposed system was compared to the conventional GSM system to validate the relationship between open loop and close loop systems.

In Fig. 3, the system is equipped with four transmit antennas $N_{T}$ and four receive antennas $N_{R}$, employing 4-QAM modulation orders, i.e. $4 \times 4$ 4-QAM. It was observed that the LC-EDAS-GSM system achieves an SNR gain of approximately $4.5 \mathrm{~dB}$ over the conventional GSM system in terms of error performance at a BER of $10^{-5}$. This is due to the exhaustive search employed by the LC-EDAS-GSM.

In addition, in Fig. 3, the LCTAS-GSM system exhibits an error performance gain of approximately $1 \mathrm{~dB}$ over a conventional GSM system. Likewise, the LC-EDAS-GSM system reveals a gain of approximately $3.5 \mathrm{~dB}$ when compared to the LCTAS-GSM system. But at a cost of higher CC due to the exhaustive search approach that was adopted by the LC-EDAS-GSM technique. The total number of transmit antenna $N_{\text {Total }}$ available is 6 , in which 4 were chosen for transmission i.e. $N_{T}=4$. 


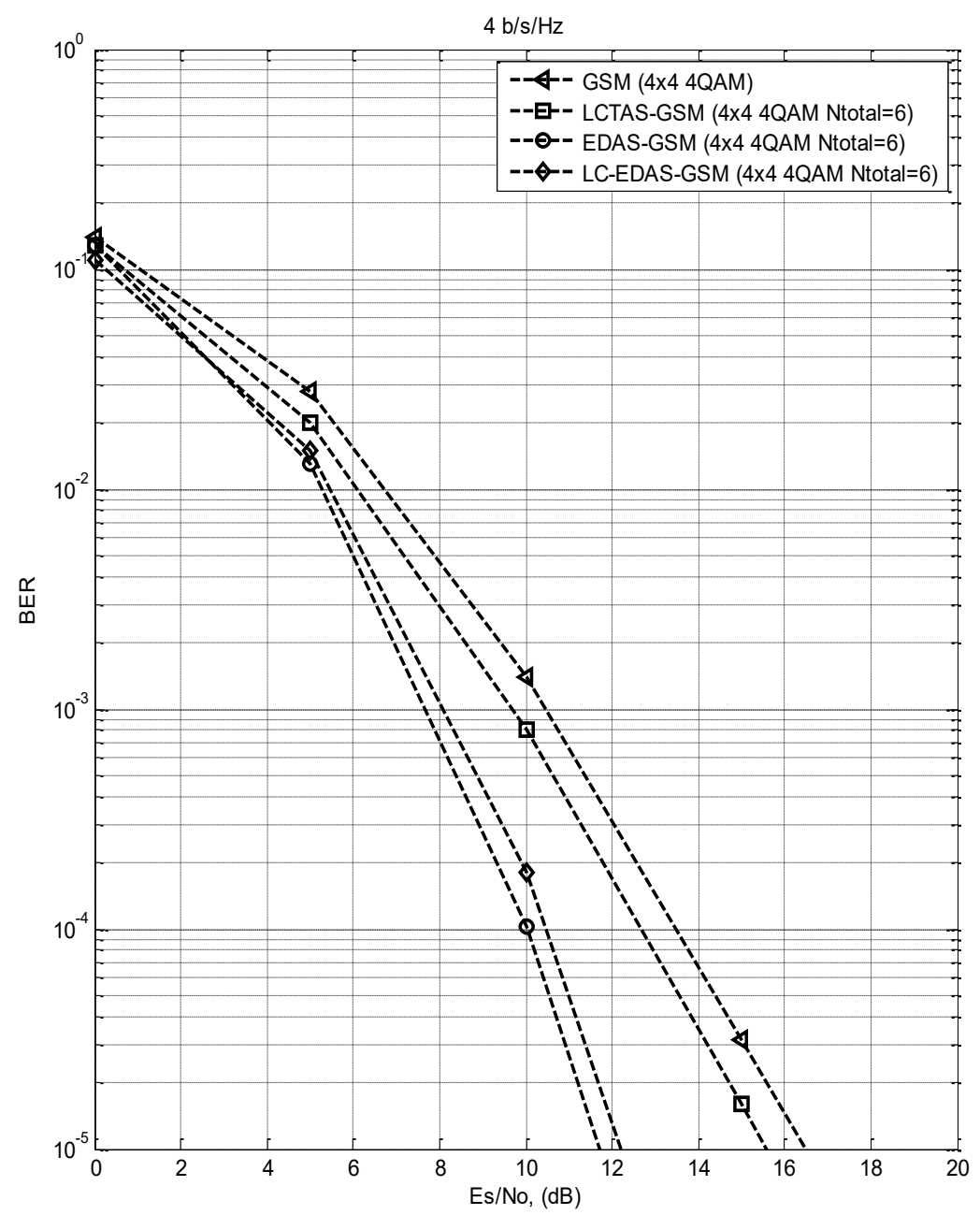

Fig. 3: BER performance comparison of GSM, LCTAS-GSM and LC-EDAS-GSM of $4 \mathrm{~b} / \mathrm{s} / \mathrm{Hz}$.

Figure 4, depicts a similar configuration to Fig. 3, a gain of approximately $6 \mathrm{~dB}$ was achieved with respect to the LC-EDAS-GSM system when compared to the conventional GSM system. This is due to the higher modulation order that was employed coupled with the high number of available transmit antennas, as GSM systems are said to exhibit a better performance with a high number of transmit antennas at high SNR region.

Likewise, considering the LCTAS-GSM system, which achieves an SNR gain of $2 \mathrm{~dB}$ over the conventional system, with a lower CC when compared to LC-EDAS-GSM system. The various variations achieved under different configurations are tabulated in Table 1.

Table 1: SNR gain achieved with respect to LC-EDAS-GSM system

\begin{tabular}{cccc}
\hline Scheme & $\mathbf{4 ~ b / s / H z}$ & $\mathbf{6 ~ b} / \mathbf{s} / \mathbf{H z}$ & $\mathbf{7 ~ b} / \mathbf{s} / \mathbf{H z}$ \\
\hline GSM & $4.5 \mathrm{~dB}$ & $6 \mathrm{~dB}$ & $5 \mathrm{~dB}$ \\
LCTAS-GSM & $3.5 \mathrm{~dB}$ & $3 \mathrm{~dB}$ & $4 \mathrm{~dB}$ \\
EDAS-GSM & $1 \mathrm{~dB}$ & $1.2 \mathrm{~dB}$ & $1 \mathrm{~dB}$ \\
\hline
\end{tabular}




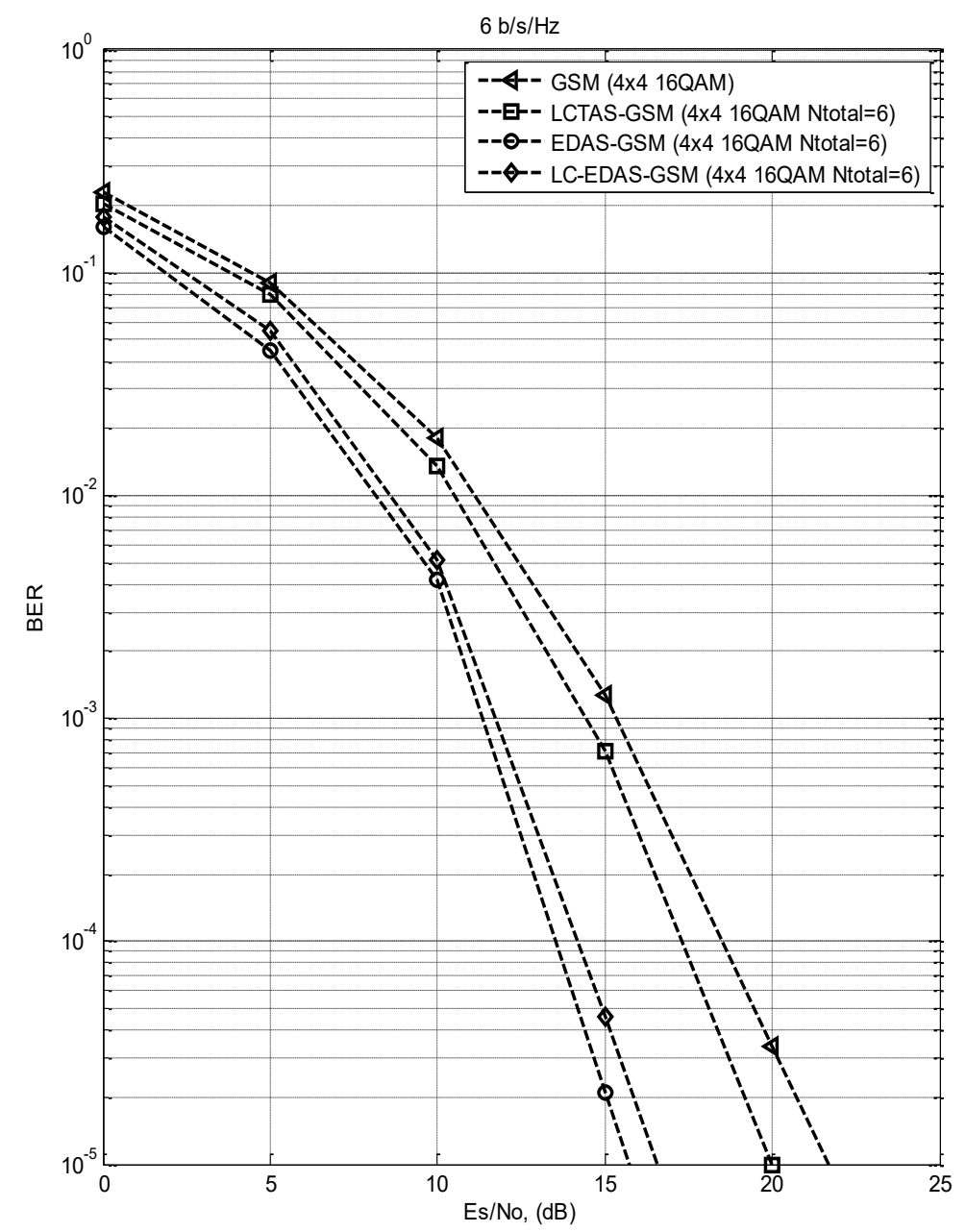

Fig. 4: BER performance comparison of GSM, LCTAS-GSM, LC-EDAS-GSM of $6 \mathrm{~b} / \mathrm{s} / \mathrm{Hz}$.

In Fig. 5, a gain of approximately $5 \mathrm{~dB}$ was achieved with respect to the LC-EDASGSM system when compared to the conventional GSM system. Likewise, considering the LCTAS-GSM system, which achieves an SNR gain of $1 \mathrm{~dB}$ over the conventional system, with a lower CC when compared to the LC-EDAS-GSM system. The total number of transmit antennas $N_{\text {Total }}$ available is 8 , in which 5 was employed for transmission i.e. $N_{T}=$ 5. The SNR gain achieved is tabulated in Table 1 with respect to the LC-EDAS-GSM system.

\section{COMPUTATIONAL COMPLEXITY}

A trade-off exists between the LC-EDAS-GSM and LCTAS-GSM in terms of CC and error performance. The CC for each TAS algorithm employed is formulated based on the floating points of operation (flops) approach similar to [10]. The CC imposed by the LCEDAS is:

I. Signal:

Evaluating the Forbenius norm in (3) requires $\left(2 N_{R}-1\right)$ flops, across $\left(\begin{array}{c}N_{\text {Total }} \\ 2\end{array}\right)$ in $N_{s}$ times. 


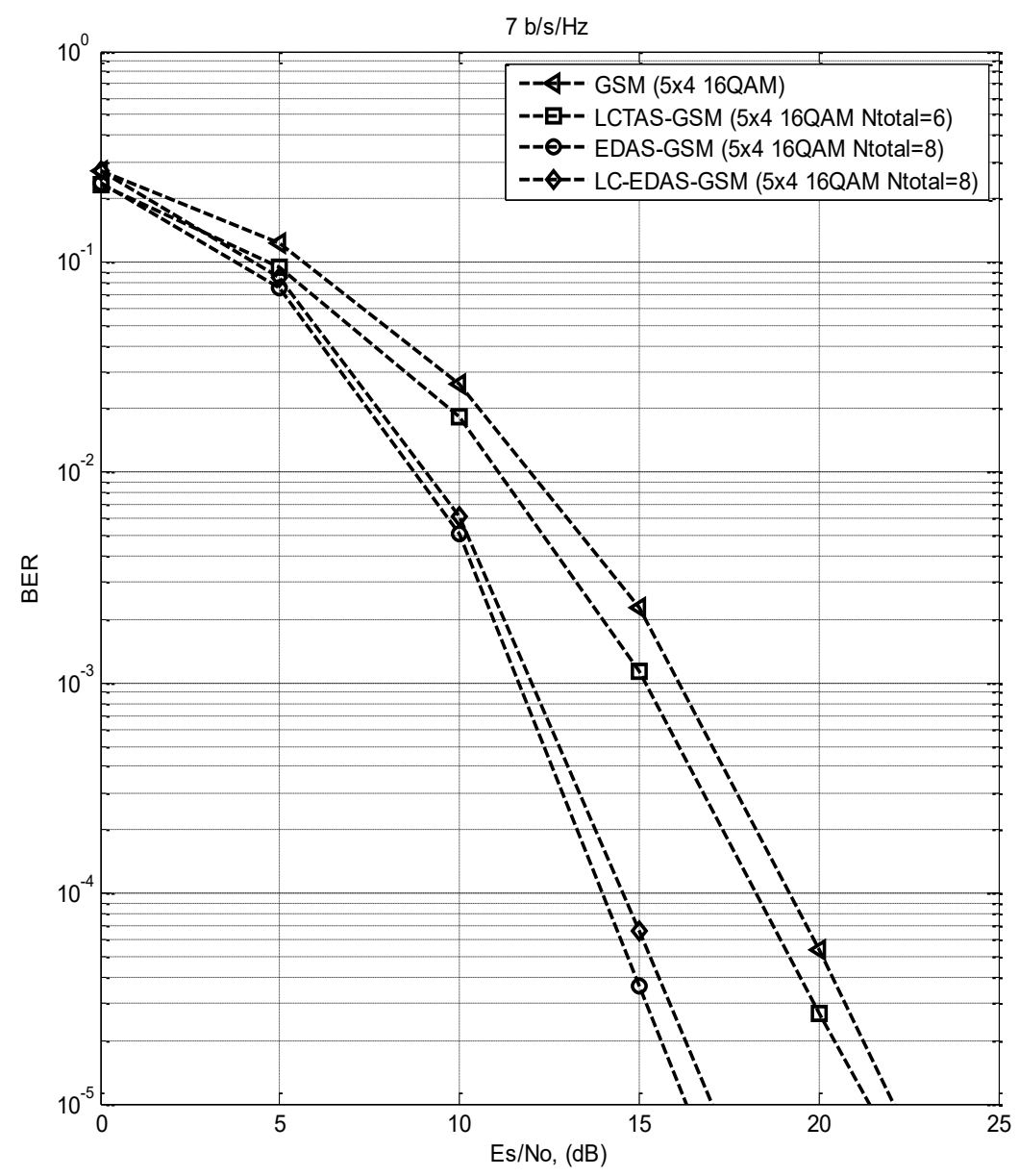

Fig. 5: BER performance comparison of GSM, LCTAS-GSM, LC-EDAS-GSM of $7 \mathrm{~b} / \mathrm{s} / \mathrm{Hz}$.

\section{Spatial:}

The CC imposed by the spatial evaluation in Eq. (4) requires $\left(2 N_{R}-1\right)$ flops to compute the square Forbenius norm, across $\left(\begin{array}{c}N_{\text {Total }} \\ 2\end{array}\right)$ in $N_{s}$ times.

III. Joint:

The joint evaluation requires $\left(2 N_{R}-1\right)$ flops in Eq. (5) and there are 4 multiplications, 1 addition, and 2 subtractions that took place within the Forbenius norm, across $\left(\begin{array}{c}N_{\text {Total }} \\ 2\end{array}\right)$ in $N_{s}$ times. The number of flops required is $\left(9 N_{R}-1\right)\left(\begin{array}{c}N_{\text {Total }} \\ 2\end{array}\right) N_{s}$.

The overall CC imposed on the system by LC-EDAS-GSM is:

$$
\delta_{L C-E D A S-G S M}=\left(13 N_{R}-4\right)\left(\begin{array}{c}
N_{\text {Total }} \\
2
\end{array}\right) N_{S}
$$

Similarly, algorithm 2 of the LCTAS-GSM approach requires $\left(2 N_{R}-1\right)$ flops across $N_{\text {Total }}$ in Step 2. Likewise, Step 4 requires $2 N_{R}+2$ flops for $\left(\begin{array}{c}N_{T}+1 \\ 2\end{array}\right)$ combinations. Therefore, the overall CC imposed by the LCTAS-GSM is: 


$$
\delta_{\text {LCTAS-GSM }}=N_{\text {Total }}\left(2 N_{R}-1\right)+\left(2 N_{R}+2\right)\left(\begin{array}{c}
N_{T}+1 \\
2
\end{array}\right)
$$

The exhaustive search requires ED to be evaluated for all symbol combinations and $4 M(4 M-1)$ flops is required for the EDAS-GSM technique across $\left(\begin{array}{c}N_{\text {Total }} \\ 2\end{array}\right) N_{s}$, imposing an overall CC of $4 M(4 M-1) N_{T}\left(2 N_{R}-1\right)+64\left(\begin{array}{c}N_{\text {Total }} \\ 2\end{array}\right) N_{S}$ flops similar to [10].

The numerical comparison in terms of complexity between both systems is computed in Table 2.

Table 2: Numerical Comparison of Computational Complexity of LC-EDAS-GSM and LCTAS-GSM

\begin{tabular}{cccc}
\hline Configuration & LC-EDAS-GSM & LCTAS-GSM & EDAS-GSM \\
\hline $\boldsymbol{M}=\mathbf{4}$ & & & \\
$N_{\text {Total }}=6$ & $\mathbf{1 0 , 8 0 0}$ & $\mathbf{1 4 2}$ & $\mathbf{2 1 , 1 2 0}$ \\
$N_{T}=4$ & & & \\
$N_{R}=4$ & & & \\
\hline $\boldsymbol{M}=\mathbf{1 6}$ & & $\mathbf{1 4 2}$ & $\mathbf{1 2 7 , 2 9 6}$ \\
$N_{\text {Total }}=6$ & $\mathbf{1 0 , 8 0 0}$ & & \\
$N_{T}=4$ & & & \\
$\boldsymbol{N}_{\boldsymbol{R}}=\mathbf{4}$ & & & \\
$\boldsymbol{M}=\mathbf{4}$ & & $\mathbf{1 9 2}$ & $\mathbf{1 0 8 , 7 5 2}$ \\
$N_{\text {Total }}=6$ & & & \\
(LCTAS) & & & \\
$N_{\text {Total }}=8($ LC- & $\mathbf{7 5 , 2 6 4}$ & & \\
EDAS) & & & \\
$N_{T}=5$ & & & \\
$\boldsymbol{N}_{\boldsymbol{R}}=\mathbf{4}$ & & & \\
\end{tabular}

\section{SUMMARY OF FINDINGS}

In this research, it is once more validated that TAS can further improve the error performance of a spatial multiplexing system. The results in this paper conform to the theory stated in the literature that TAS, a closed loop system, can maximize transmit diversity. In Table 1, LC-EDAS-GSM achieves up to approximately $5 \mathrm{~dB}$ and $4 \mathrm{~dB}$ SNR gain at a bit error rate (BER) of $10^{-5}$ of $4 \mathrm{~b} / \mathrm{s} / \mathrm{Hz}$ configuration setting when compared to LCTAS-GSM and the conventional GSM system, respectively. In addition, EDAS-GSM outperforms other TAS techniques employed, due to the exhaustive search. However, the system gain is thus reduced as the spectral efficiency increases, due to the high modulation order employed, as seen in Fig. 3 and Fig. 4, respectively. Likewise, Table 2 presents the numerical comparison of both TAS techniques, in which LCTAS-GSM imposed a lower CC with the same configuration settings in LC-EDAS and EDAS-GSM imposed a high CC when compared to other techniques employed. This is because the EDAS CC is a function of the modulation order $\boldsymbol{M}, \boldsymbol{N}_{\text {Total }}$, and $\boldsymbol{N}_{\boldsymbol{R}}$ while LCTAS and LC-EDAS are functions of just $\boldsymbol{N}_{T}$ and $\boldsymbol{N}_{\boldsymbol{R}}$

\section{CONCLUSION}

This research demonstrated the applicability of transmit antenna selection in improving the reliability/error performance of a MIMO based scheme. It was evident from the Monte 
Carlo simulation results that were obtained that the GSM system equipped with TAS can achieve a significant enhancement over the conventional GSM system.

To attain a similar result with less CC than the conventional EDAS algorithm, which employs an exhaustive search across all channel combinations to achieve an optimal performance, an LC-EDAS TAS algorithm, which splits the process into spatial, signal, and joint evaluation was employed.

\section{REFERENCES}

[1] Simon M. K. (2010) Digital Communication over Fading Channels. Hoboken, WileyInterscience Publication.

[2] Goldsmith A. (2005) Wireless Communications. Cambridge, Cambridge University Press.

[3] Mesleh R. Y, Haas H, Sinanovic S, Chang Wook A, and Sangboh Y. (2008) Spatial Modulation. IEEE Transactions on Vehicular Technology, vol. (57): pp. 2228-2241.

[4] Younis A, Serafimovski N, Mesleh R, and Haas H. (2010) Generalised Spatial Modulation. In Proceedings of Conference Record of the Forty Fourth Asilomar Conference on Signals, Systems and Computers, November 7-10, 2010; Pacific Grove, California. Edited by Michael B. Matthews, ATK Mission Research; pp. 1498-1502.

[5] Mesleh R, Ikki S. S, and Aggoune H.M. (2014) Quadrature Spatial Modulation. IEEE Transactions on Vehicular Technology, vol (64): pp. 2738-2742.

[6] Mesleh R, and Ikki S. S (2014) A High Spectral Efficiency Spatial Modulation Technique. In Proceedings of IEEE 80th Vehicular Technology Conference, 14-17 September 2014; Vancouver.

[7] Jintao W, Shuyun J and Jian S. (2012) Generalised Spatial Modulation System with Multiple Active Transmit Antennas and Low Complexity Detection Scheme. IEEE Transactions on Wireless Communications, vol (11):pp. 1605-1615.

[8] Rajashekar R, Hari K. V. S and Hanzo L. (2013) Antenna Selection in Spatial Modulation Systems. IEEE Communications Letters, vol. (17):pp. 521-524.

[9] Xu H, Naidoo N.R, and Quazi T. (2010) Spatial Modulation: optimal detector asymptotic performance and multiple-stage detection. IET Proceedings - Communications, vol. (10):pp. $1368-1376$.

[10] Xu H, Pillay N. (2014) Low Complexity Detection and Transmit Antenna Selection for Spatial Modulation. SAIEE Africa Research Journal, vol(105):pp. 4-12.

[11] Yang P, Guan Y. L, Xiao Y, Di Renzo M, Li S, and Hanzo. L (2015) Transmit Pre-coded Spatial Modulation: maximizing the minimum euclidean distance versus minimizing the bit error ratio. IEEE Transactions on Wireless Communications, vol. (32):pp. 1-15.

[12] Yang P, Guan Y. L, Xiao Y, Li S, and Hanzo. L (2016) Transmit Antenna Selection for Multiple-Input Multiple-Output Spatial Modulation Systems. IEEE Transactions on Communications, vol. (64): pp. 2035-2048.

[13] Di Renzo M, and Haas H. (2010) Improving the performance of space shift keying (SSK) modulation via opportunistic power allocation. IEEE Communications Letters, vol.(14): pp. 500-502.

[14] Yang P, Xiao Y, Di Renzo M, Li S, and Hanzo. L (2015) Design Guidelines for Spatial Modulation. IEEE Communication Surveys and Tutorials, vol.(17):pp. 6-26.

[15] Xu H, Pillay N. (2015) Low-Complexity Transmit Antenna Selection Schemes for Spatial Modulation. IET Communications, vol.(9):pp. 239-248.

[16] Nan W, Wenlong L, Hongzhi M, Minglu J, and Hongjun X. (2014) Further Complexity Reduction Using Rotational Symmetry for EDAS in Spatial Modulation. IEEE Communications Letters, vol. (18): pp. 1835-1838.

[17] Ping Y, Yue X, Lei L, Qian T, Yi Y, and Shaoqian L. (2012) Link Adaptation for Spatial Modulation With Limited Feedback. IEEE Transactions on Vehicular Technology, vol.(61): pp. 3808-3813. 
[18] Ntontin K, Di Renzo M, Perez-Neira A. I, and Verikoukis C. (2013) A Low-Complexity Method for Antenna Selection in Spatial Modulation Systems. IEEE Communications Letters, vol. (17): pp. 2312-2315.

[19] Xu H, Pillay N. (2016) Improved Generalized Spatial Modulation via Antenna Selection. International Journal of Communication Systems, vol. (30).

[20] Zhou Z, Ge N, and Lin X. (2014) Reduced-Complexity Antenna Selection Schemes in Spatial Modulation. IEEE Communications Letters, vol. (18): pp. 14-17.

[21] Jianping Z. (2012) Signal Vector Based List Detection for Spatial Modulation. IEEE Wireless Communications Letters, vol. (1): pp. 265-267.

[22] Xu H, Pillay N. (2013) Comments on Signal Vector Based Detection Scheme for Spatial Modulation. IEEE Communications Letters, vol. (17): pp. 2-3. 